Journal of Al-Azhar University Engineering Sector

Vol.15, No. 55, April, 2020, 475-488

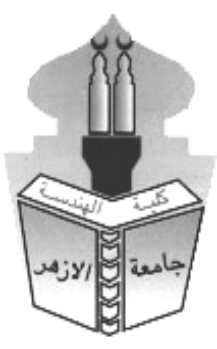

\title{
L-SHAPED MECHANICAL COUPLER FOR RC CORNER JOINT
}

\author{
Ahmed Yaseen Al-Tuhami ${ }^{* 1}$, Ahmed Ghalab ${ }^{1}$, Soliman Ali-Eldin ${ }^{2}$ and Al-Tuhami Abuzeid ${ }^{3}$ \\ ${ }^{1}$ Structural Department, Faculty of Engineering, Ain-Shams Universilty, Cairo, Egypt. \\ ${ }^{2}$ Mechanical Design Department, Faculty of Engineering, Zagazig University, El-Sharkia, Egypt. \\ ${ }^{3}$ Structural Department, Faculty of Engineering, Zagazig University, El-Sharkia, Egypt. \\ *Corresponding Author: E-mail: ahmedyaseen772@outlook.com.
}

\begin{abstract}
ABSRACT
The main aim of this research is to design and manufacture L-shaped mechanical couplers to connect two perpendicular reinforcing bars in knee joint instead of cold-bending bars at the corner of this joint. Each branch of the two L-shape coupler branches equipped with threaded holes coincide with the prepared threading of the enlarged reinforcing bar end. Therefore, the reinforcing bars that were coupled by the L-shaped mechanical couplers were used in reinforcing the closing corner joint.
\end{abstract}

\section{KEYWORDS: Reinforced Concrete, Knee Joint, L-Shaped Mechanical Coupler, Experimental Work. Cold bending}

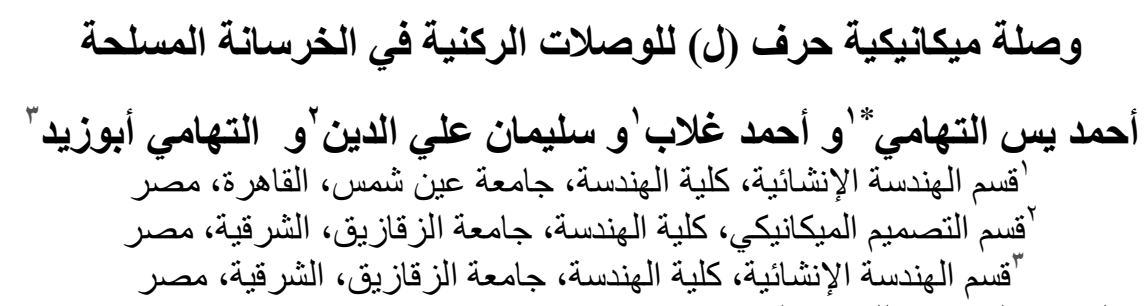

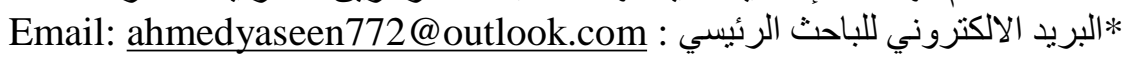

نتيجة لثني أسياخ صلب التسليح علي البارد تتغير الخواص الميكانيكية لتلك الأسياخ وتثيخ تلاك المنطقة ويتغير سلوكها من

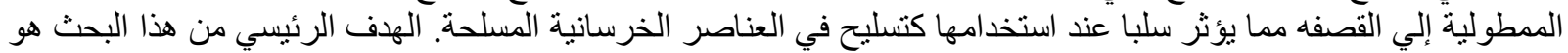

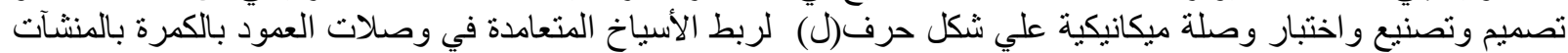

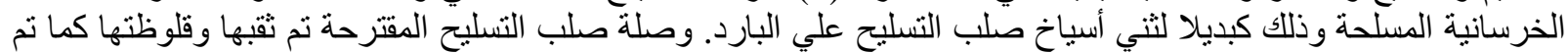

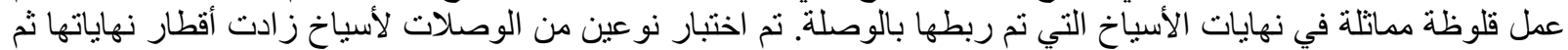

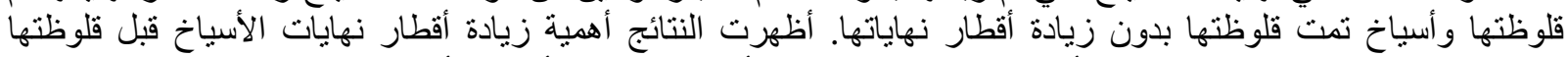

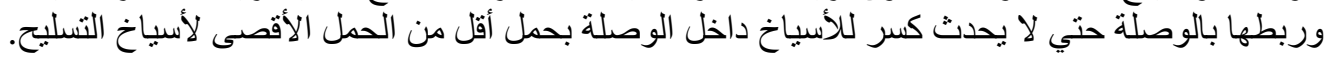

الكلمات المفتاحية: الخرسانة المسلحة ،الوصلات الركنية ، الوصلات الميكانيكية لأسياخ التسليح علي شكل حرف (ل) ، اختبارات معملية. الثي على البارد 


\section{INTRODUCTION:}

The reinforced concrete knee joint consists of one beam and one column connected at their ends, forming commonly a 90" angle. Knee joint is a critical zone because of resisting large forces during different load cases and transfer stresses throw the adjoining member. The problem is that the joint need to be of high ductility, stiffness and energy dispersion which is difficult to achieve in joint. Another problem is the difficulty of maintaining the joint after being damaged. However, because of these problems, many researchers have been studied many reinforcement details, reinforcement ratios and different concrete grades to improve the performance and ductility of corner joint. It had been found that [1], low efficiencies for specimens with high reinforcement ratios in knee joint, whereas cracks started in outer joint forming diagonal cracks causing failure. And the failure occurred suddenly and brittle manner.

It was reported that [2] the efficiency increased when a lower reinforcement to concrete ratio to be less than 1\%. A confined diagonal compression strut was suggested [3] to avoid the spalling and crushing of concrete in this region as well as increases the ductility of knee joint. The reinforcement loop was studied [4] in knee joint. It was observed that, the risk of spalling of concrete cover increased and the corner joint efficiency was decreased.

The reinforcement details in the corner joint usually have a bending of the main reinforcing bars. The cold bending occurred when a mechanical torque is applied directly to reinforcing bars in room temperature. This process produces tension stresses in the outer fibers and compression stresses in the inner fibers. However, the cold bent region suffers from strain aging and hardening. Where the tensile tests were performed on cold bend specimens, strain aging resulted in a shifting of fracture mode from ductile to brittle as a function of energy transition [5,6]. The stress distribution during cold bending and its affect on the bar ductility are shown in Fig 1. Therefore, strain aging causes prematurely fracture and reduces susceptibility of sustaining in elastic deformation. The changed of mechanical properties due to bending bar process is converted from ductile to brittle manner as a function of energy transmission.

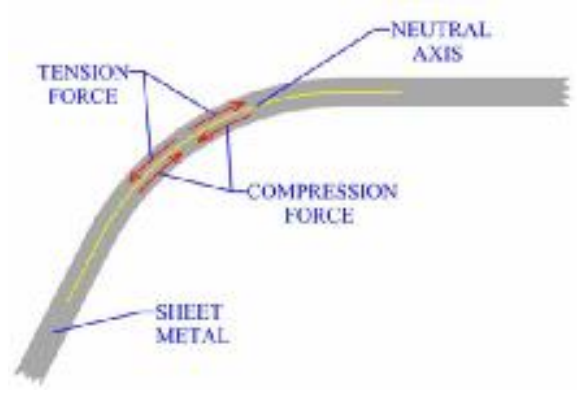

a)

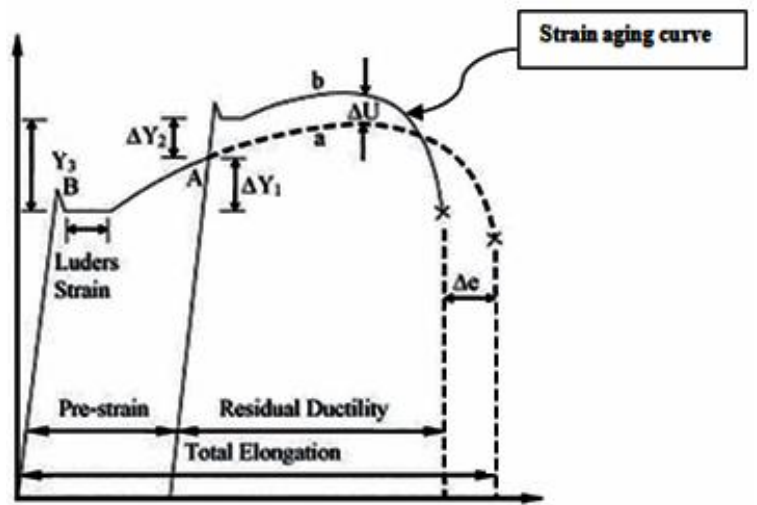

b)

Figure 1: Effect of cold bending on rebar, a) stress distribution during cold bending and b) effect of cold bending on the reinforcing bar ductility, (G.T Van Rooyen, 1986).

So many researches [7, 8] produce artificial aging of rebar specimens by increasing the temperature $100^{\circ} \mathrm{C}$ or $150^{\circ} \mathrm{C}$ to simulate the change of mechanical properties with time passing. Those researchers found that the bending process leads to the occurrence of strain aging causing unexpected sudden failure in bending region. A tensile test of bent bars was conducted [9] containing different proportions of vanadium after one and three months, the results of the test specimens after three months showed that the ductility decreases more than that obtained after one month.

The quantification of micro cracks that occurred as a result of bending a high-strength steel plate and mild steel one was studied [10]. It was found that the cracks increased when bending the high- strength steel compared to the mild steel. 
The high performance steel bar in a shape of closed stirrups was studied under tensile test [11]. One side of the bent region stirrup was coated by a rubber material. The two bent portion of the prepared stirrup were covered by two concrete blocks. Hydraulic jack was placed between the two concrete blocks to apply compression forces on specimens. The result of test illustrated that reinforcing bars were failed at the bent portion that covered by the rubber martial. The idea of using the L-shaped mechanical coupler to overcome the structural problems arising from cold bending of reinforcing bars was suggested in the international patent application number WO/2016/138912, [12]. Mechanical coupler transfers tension and compression loads from one piece of reinforcement to another. The success of the mechanical couplers depends on the capacity load of the mechanical coupler which must not be less than the capacity load of bar. ACI 318-2011, section 12.15.5, states, "A full mechanical connection shall develop in tension or compression, as required, at least 125 percent of the specified yield strength of the bar". Therefore, the failure mode should occur outside of the mechanical coupler and should not fail under the bearing and slipping in the coupling portion of the rebar. Do-Kyu et al., (2015) It was concluded that, [13], the threads of the threaded rebar coupler system could be loosened while exposed tension-compression cyclic loading because the tolerance and the rib face angle of a threaded rebar coupler system are greater than that of a conventional ribbed rebar. Nguyen and Mutsuyoshi (2015) It was concluded that [14], as the threaded length increase of coupled portions of the rebar inside the coupler, enhancement was observed on the coupler-rebar system load and ductility capacities. Harinkhede et al., (2016) concluded that, The threaded mechanical coupler made from the high carbon steel subjected to tensile test achieve more satisfactory results than that obtained of mild steel, [15].

The purpose of this research is to fabricate and test the threaded 1-shaped mechanical coupler to be used in reinforced concrete structural elements especially in knee corner joints.

\section{MANUFACTURING OF L-SHAPE COUPLER:}

L-shaped mechanical coupler was designed, manufactured and used to connect perpendicular reinforcing main bars as substitute of bending the steel bars in the knee corner joint. The threaded technique, method was used to connect the perpendicular reinforcing bars with the mechanical coupler. The main design requirements that were addressed in this study include:

a) The load capacity and ductility of the coupler material not less than that of the rebar,

b) The strength of the mechanical joint ensures that the fracture occur in the reinforcing bars outside the threading portion.

c) The bar end threaded and the internal threaded of the mechanical coupler achieves complete interfere between them in order to prevent slippage that may occur during loading.

\subsection{Rebar and coupler material:}

In this study, the material of mechanical coupler was selected from plates of steel which is the same steel grade of the reinforcing bars. In order to check the mechanical properties of the coupler material, a strip with a length of $380 \mathrm{~mm}$ was taken from the same steel plate. The strip specimen was converted from cuboid shape to cylindrical shape with a cross-section diameter of $12.5 \mathrm{~mm}$ by using the lathe machine. The tensile test results showed that the yield stresses were close to each other, while the stiffness and ductility of the coupler material were greater than that of the reinforcing bars. Figure 2 shows the failure mode of the coupler specimen material while stress-strain curve of the test specimen is shown in Figure 3.
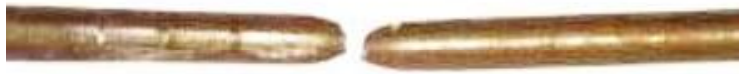

Figure 2: Failure mode of the mechanical coupler material specimen. 


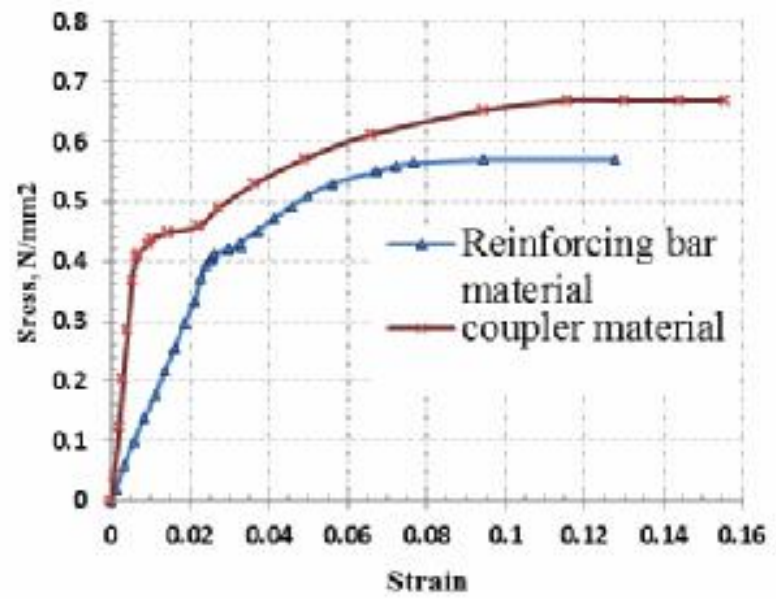

Figure 3: Stress-strain curve of the mechanical coupler and bar material.

\subsection{Preparation of reinforcing bar ends and threads profile:}

The main reinforcing steel in tension sides of the test specimens was of grade B400DWR Ribbed Bars (standard 262/2015). The threading process was done at the ends of the reinforcing bars (18 $\mathrm{mm}$ diameter) that coupled by mechanical coupler. As well known the threading process is taking out from the reinforcing bar body, therefore, the nominal size as well as the load capacity decreases. So the coupled part of steel bar ends were enlarged first, then the threading process was carried out. The enlargement process of the bar end portions is done using hot forging to obtain good mechanical properties of this portion of the bar end. The final maximum and nominal diameters of the enlargement threaded bar ends are 19.5 and $18 \mathrm{~mm}$ respectively. Three of the reinforcing rods were directly threaded without enlargement, the maximum and nominal diameters were 17.5 and $16 \mathrm{~mm}$ respectively. Figure 4 and 5 shows the dimensions of the threaded portion of the bars end with and without enlargement.

ISO metric threaded type was used in both internal thread of the coupler and external thread of the reinforcing rod ends. This type of threads is defined in international standard ISO 68-1.

The length of thread depends on diameter of steel bar strength which ranging from 1.25 to 1.5 the reinforcing bar diameter. Therefore, for a rod with a diameter of $19.5 \mathrm{~mm}$, the chosen threading length is $29.25 \mathrm{~mm}$.

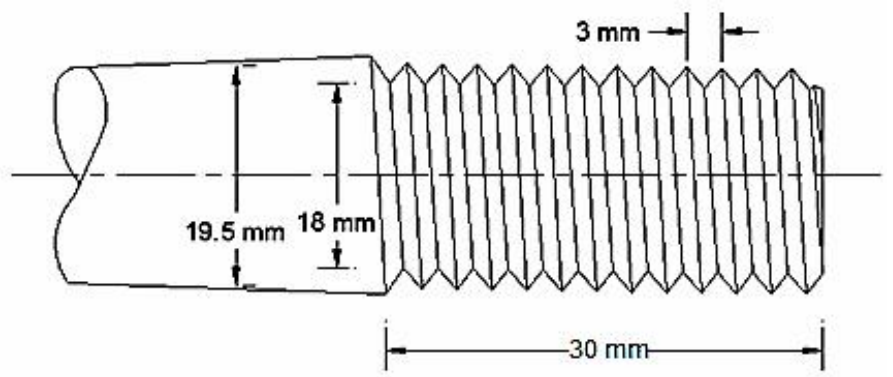

Figure 4: The threaded detail dimension for enlarged bar end. 


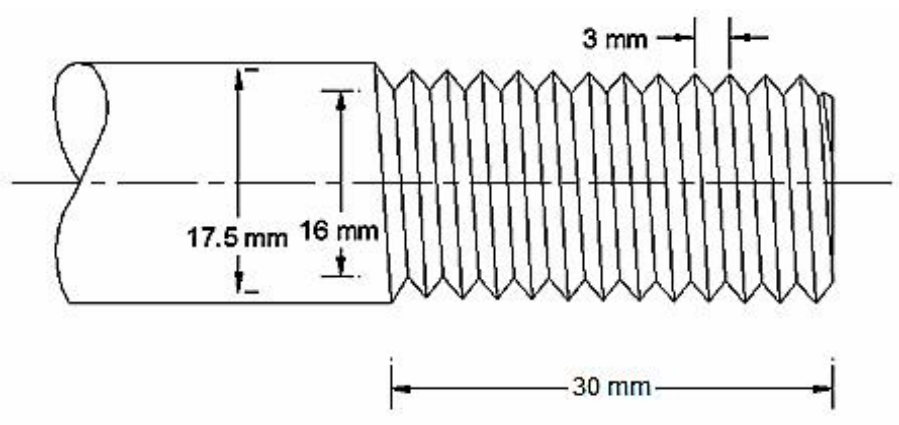

Figure 5: The threaded detail dimension for not enlarged bar end.

\subsection{Cross-section area requirement of the mechanical coupler branches:}

ACI 318, Section 12.14.3.4, states: "A full mechanical connection shall develop in tension or compression, as required, at least 125 percent of specified yield strength $f_{y}$ of the bar". Since the mechanical properties of the coupler material are close to that of the reinforcing bar, the coupler was designed so that the net area of the threaded part of the coupler at least equal to 1.25 times the cross-section area of the rebar.

To demonstrate the importance of increasing the diameter of the end portion of the reinforcing bar and its effect on the load capacity and failure mode, the tests included three bars that were not increased in diameter and four bars with enlarged diameters.

Figure 12 illustrates the internal and external dimensions for the coupler branches cross-sections of two L-shaped couplers. These two types are to connected enlarged and non-enlarged reinforcing bars. In the two cases, the net cross-section area of each branch of L-shaped coupler is greater than 1.25 times the cross-section area of the bar to be coupled.

\subsection{Manufacturing steps of mechanical L-shape coupler:}

The process of manufacturing the mechanical L-shaped coupler has gone through many steps, including the selection of steel plate, cutting in the required form, the process of drilling the holes and then making the internal threading as follows:

a. Using the CNC Plasma cutting machine, L-shape strips were taken out with required dimension from a steel plate with thickness $30 \mathrm{~mm}$. Figure 6 showed the CNC plasma cutting machine during cutting the pieces, while the shape of specimens after cutting process was shown in Figure 7.

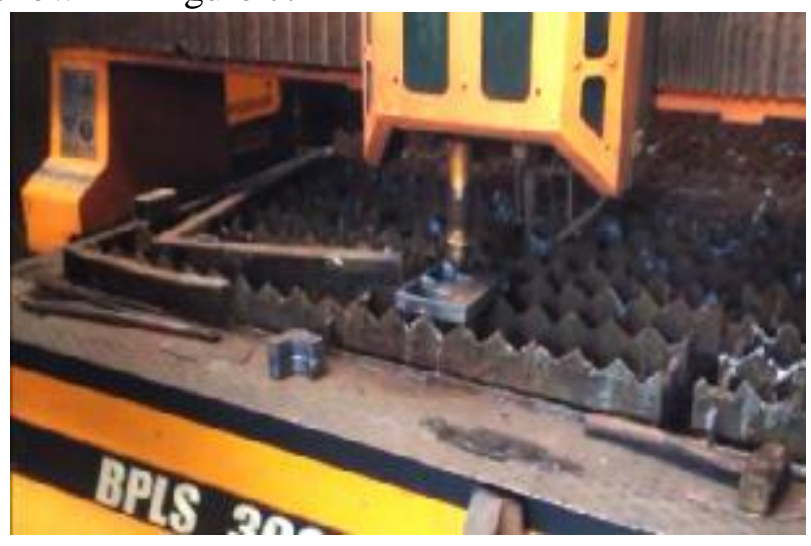

Figure $6 \mathrm{CNC}$ plasma machine during cutting process.

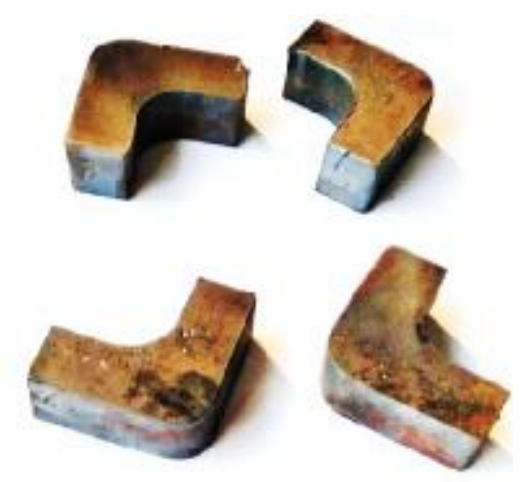

Fig 7: The shape of specimens after cutting process. 
L-SHAPED MECHANICAL COUPLER FOR RC CORNER JOINT

b. Holes were made in the branches of the two coupler types as shown in Figure 10. The holes are made along the longitudinal axis of each branch started from the leg end. The depth of each hole was $30 \mathrm{~mm}$ while the diameters are $19 \mathrm{~mm}$ and $17.5 \mathrm{~mm}$ according to coupled bars, enlarged or non-enlarged bar respectively. The larger diameter used to connect the bars that have been enlarged diameter and vice versa. Figure 8 shows the holes were done by Lathe machine.

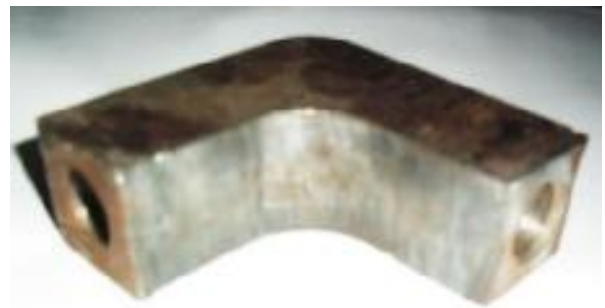

Figure 8: Two holes performed by Lath machine in the two coupler branches.

c. The L-shape piece was converted from cuboid shape to cylindrical shape using the CNC Milling Machines. Figure 9 shows the shape of mechanical coupler after this process.
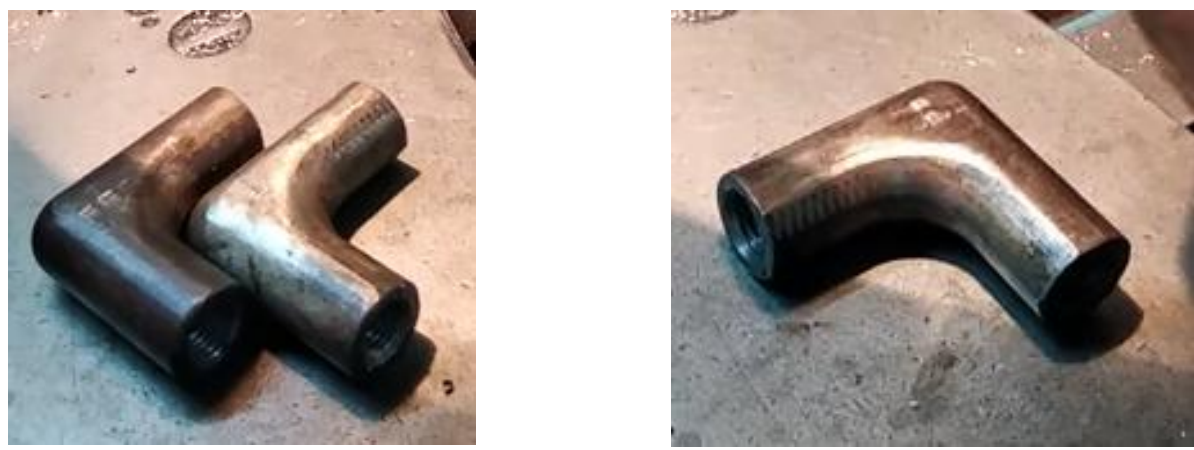

Figure 9: Shape of primary development of mechanical coupler.

d. The L-shape mechanical couplers were then internally threaded in the two coupler branches matching the threads were made on the reinforcing bar ends to be coupled by using lathe machine. Figure 10 shows threading process using the lathe machine. Figure 11 shows the dimensions on the cross-sectional elevation of the L-shape coupler.

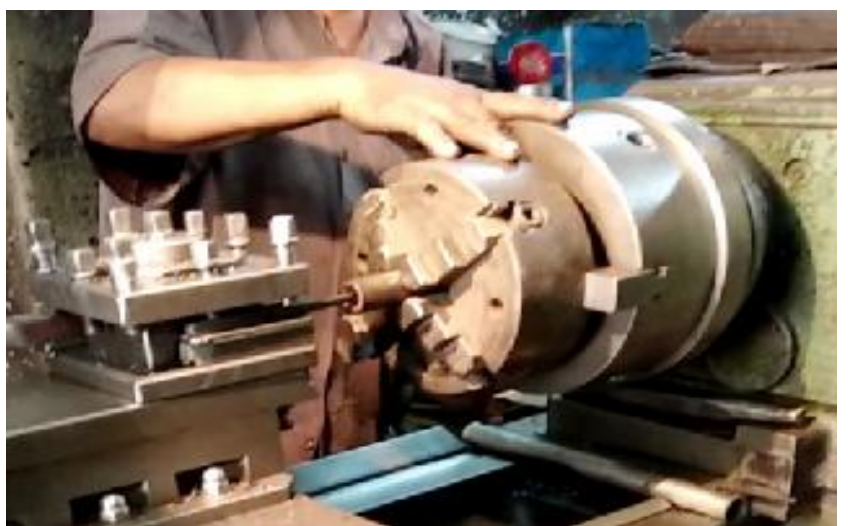

Figure 10: Process of internal threading using the lathe machine. 

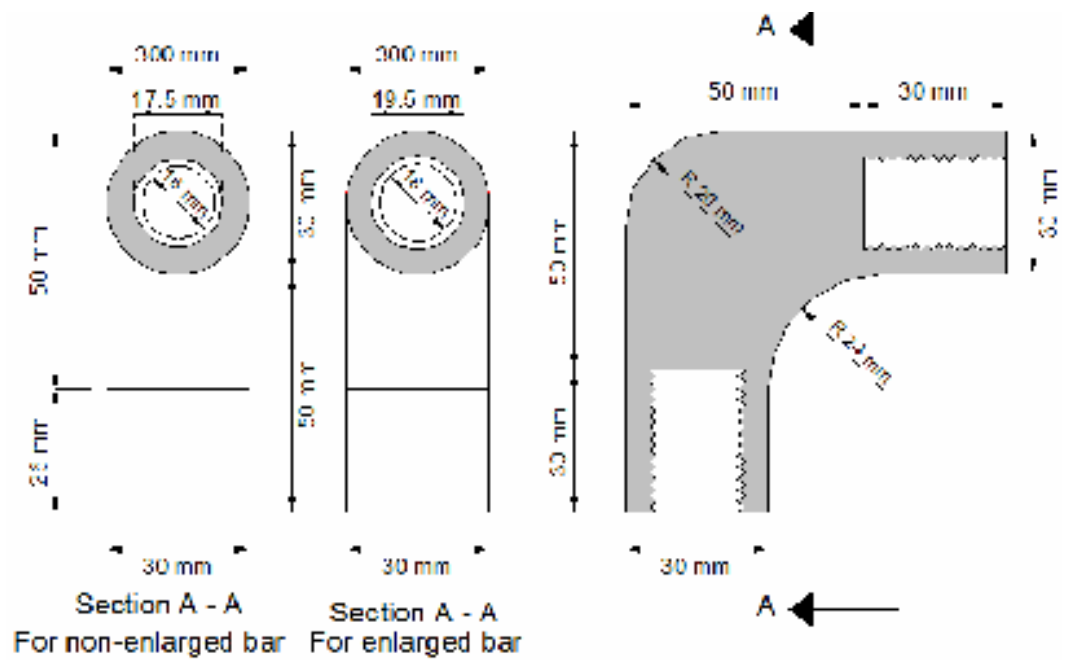

Figure 11: Cross-section elevations and side view of coupler branches to connect non-enlarged and enlarged bar ends respectively.

\section{PREPARATION OF REINFORCING BAR ENDS}

\subsection{Enlargement the coupling part of the reinforcing end bars:}

As stated before, the hot forge process was used to enlarge the coupled parts of rebar ends for obtaining good mechanical properties for the enlarged portions.This operation was performed manually as follows:

a. The ends of the reinforcing bars have been heated at a temperature of about 700 degrees Celsius.

b. The rebar's then knocked while hot until the end portion reach to conical shape with the diameter ranges from $25 \mathrm{~mm}$ to $22 \mathrm{~mm}$ with length of $4 \mathrm{~cm}$. Figure 12 shows knocking a reinforcing rebar after heated its end while Figure 13 shows the shape of bars after enlargement process.

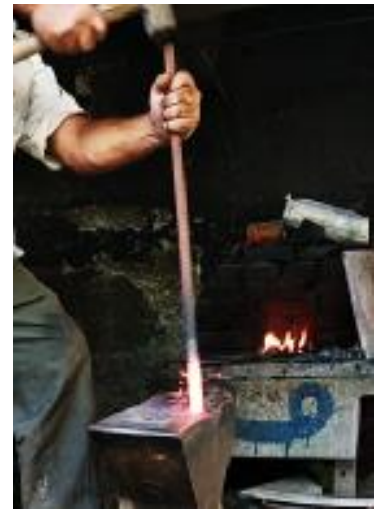

Figure 12: Knocking a heated reinforcing bar end.

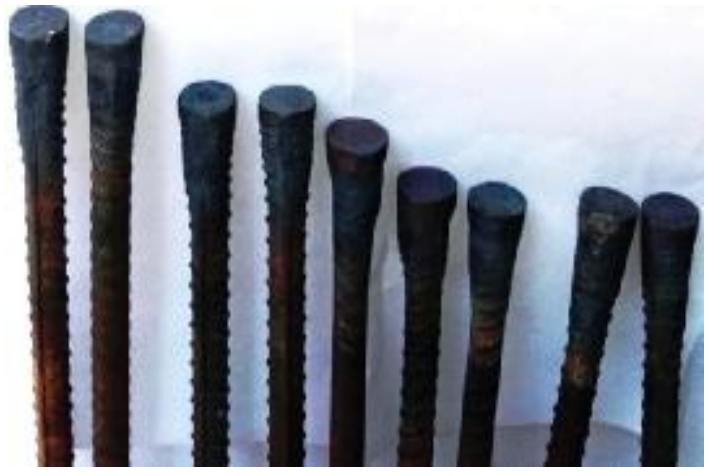

Figure 13: The reinforcing bars after enlargement process. 


\subsection{Threading Of Bar Ends For Enlargement And Non-Enlargement Reinforcing Bars:}

a. Threading was done on the ends of the reinforcing bars, which were set to end with a length of $3 \mathrm{~cm}$ using the lathe machine. The threading dimensions and configurations matching to the threading that were made in the mechanical coupler. Figure 14 shows the reinforcing steel bars during the process of threading.

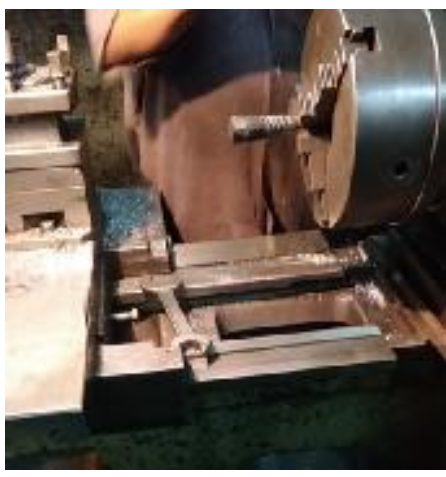

a)

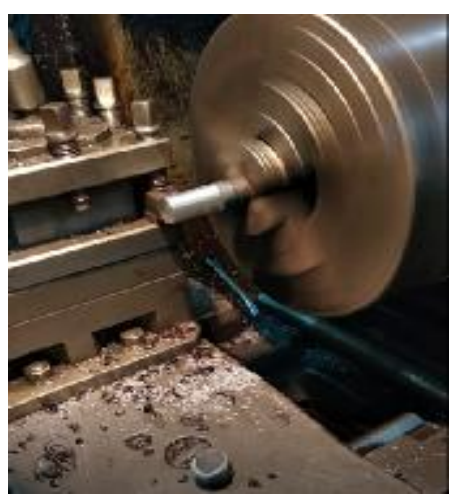

c)

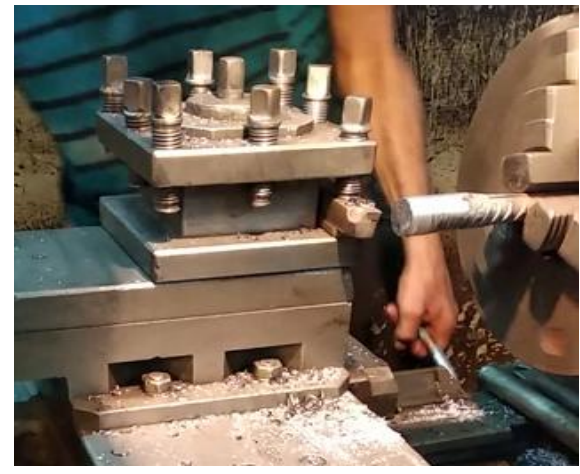

b)

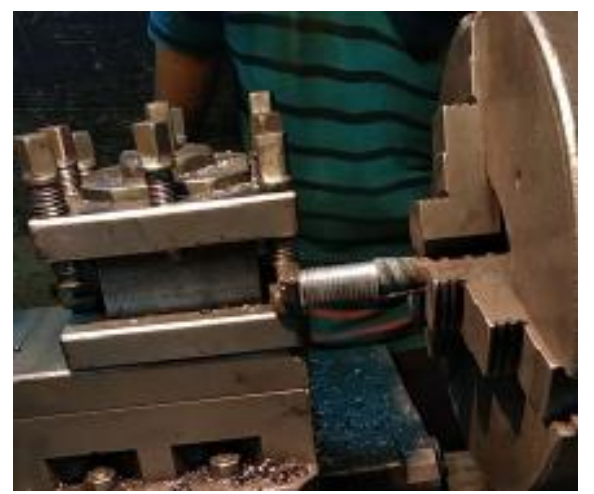

d)

Figure 14: Steps of enlarged rebar threading using Lath machine.

b. $\quad$ For reinforced steel bars that have not been enlarged, the rebar are made directly by using the lathe machine to match the thread that were made on the mechanical coupler. Figure 15 shows the process of threading of non- enlarged bar. 


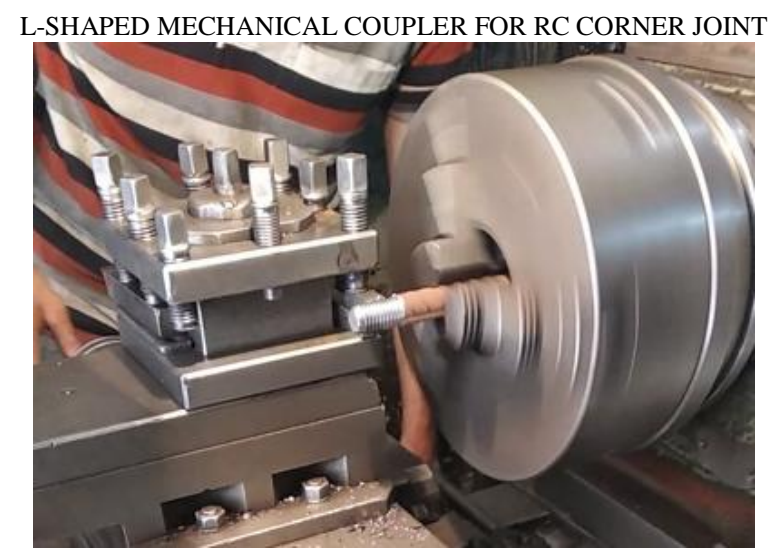

Figure 15: The process of threaded not enlarged rebar.

c. The ends of the bars were connected to the mechanical coupler by applying the prescribed torque.

\section{TESTING THE PRODUCED L SHAPED MECHANICAL COUPLER:}

The purpose of the L-shaped mechanical couplers is to connect two ends of two perpendicular reinforcing bars for transferring the stresses between them instead of using one bar bent in an Lshape. The strength of the mechanical joint should ensure that the fracture occurs in the reinforcing bar outside the threading portion (couplingportion). In addition, the produced coupler should behave better to prevent any slippage between the bar and the mechanical coupler. A tensile test was conducted for six branches of mechanical couplers to demonstrate the importance of increasing the diameter of the end portion of the reinforcing bar and its effect on the load capacity and failure mode. The tests included three bars that were not enlarged its diameter and four bars with enlarged diameters. The details of these specimens are shown in Table 3.1.

For the non-enlarged bar end diameter specimens, the results showed that, in two specimens, the reinforcing bars failed in threaded part inside the coupler. This result is attributed to the nominal diameter in the threaded part is the weakest portion of the reinforcing bar where the nominal diameter in threaded part is $16 \mathrm{~mm}$ while the bar diameter is $17.5 \mathrm{~mm}$. The yield loads of these test specimens were 103 and $105 \mathrm{kN}$ while the ultimate loads were $113 \mathrm{kN}, 117 \mathrm{kN}$ respectively. The third specimen failed by slipping the reinforcing bar from the mechanical coupler at load 130 $\mathrm{kN}$ as shown in Figure 16-b.The reason for the slippage is that the dimensions of the threading teeth are not enough to resist slipping load.

For enlarged bar end diameter specimens, the fracture occur in the reinforcing rod outside the coupling portion in all the specimens. The ultimate loads were 135,135 and $140 \mathrm{kN}$. Only one portion of coupler connected to enlarged end bar failed inside coupler at threaded region at load $132.5 \mathrm{kN}$ as shown in figure 16-d. The reason of this failure is a notch on the bar threading due to manufacturing defect which cause the stress concentration at this notch. The ultimate, yield loads and failure mode for test specimens are shown in Table 1 . Figure 16 a,c shows the failure mode for Two L-shape mechanical coupler one of branch for each L-shape coupler connected to non enlarged end bar is failed at inside braches of coupler and the other branch connected to enlarged end bar is failure out of coupler. 


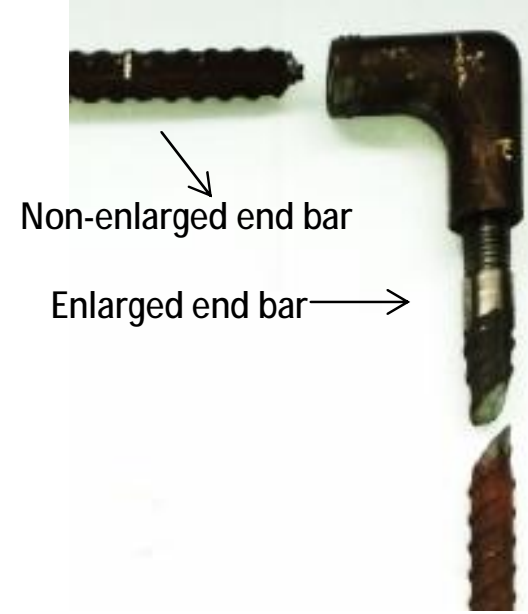

a)

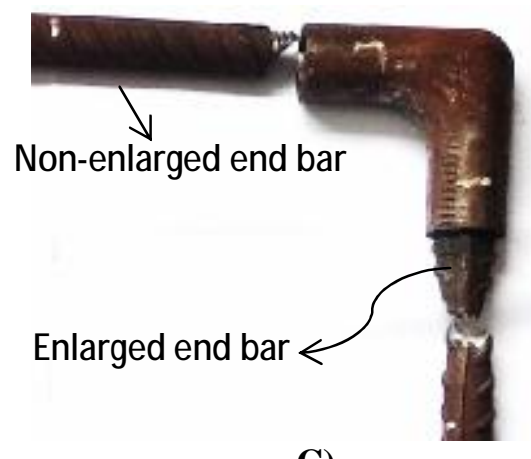

C)

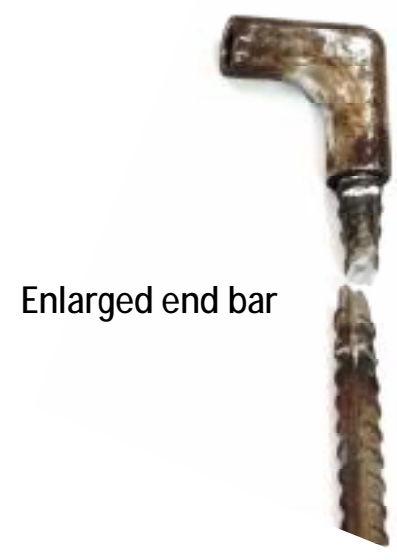

e)

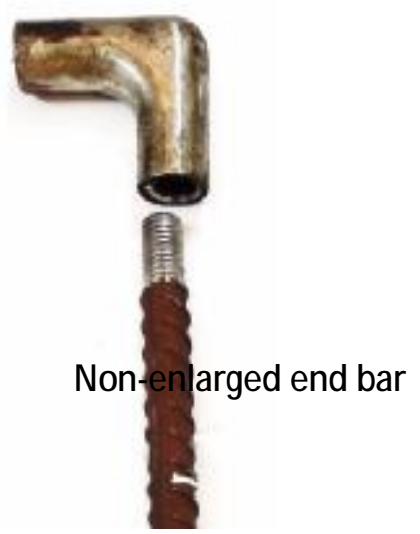

b)

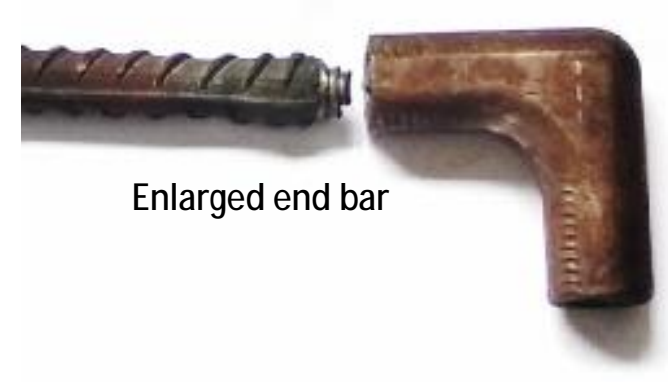

d)

Figure 16: failure mode for L-shape couplers with enlarged or nonenlarged bar. 
L-SHAPED MECHANICAL COUPLER FOR RC CORNER JOINT

Table 1: Ultimate and yield load and failure place within or outside coupler.

\begin{tabular}{|c|c|c|c|c|c|c|}
\hline \multirow{2}{*}{$\begin{array}{c}\text { Figure } \\
\text { No. }\end{array}$} & \multicolumn{2}{|c|}{ Bar end type } & \multirow{2}{*}{$\begin{array}{c}\text { Yield } \\
\text { load, } \\
\text { kN }\end{array}$} & \multirow{2}{*}{$\begin{array}{l}\text { Ultimate } \\
\text { load, kN }\end{array}$} & \multicolumn{2}{|c|}{ Failure place } \\
\hline & Enlarged & $\begin{array}{c}\text { Non- } \\
\text { enlarged }\end{array}$ & & & $\begin{array}{l}\text { Coupled } \\
\text { portion }\end{array}$ & $\begin{array}{l}\text { Outside } \\
\text { coupler }\end{array}$ \\
\hline $17-c$ & $\sqrt{ }$ & & 105 & 140 & & $\sqrt{ }+\sqrt{ }$ \\
\hline $17-c$ & & $\sqrt{ }$ & 105 & 117 & $\sqrt{ }$ & \\
\hline $17-a$ & $\sqrt{ }$ & & 105.5 & 135 & & $\sqrt{ }$ \\
\hline $17-a$ & & $\sqrt{ }$ & 103 & 113 & $\sqrt{ }$ & \\
\hline $17-e$ & $\sqrt{ }$ & & 107 & 132.5 & $\sqrt{ }$ & \\
\hline $17-d$ & $\sqrt{ }$ & & 104 & 135 & & $\sqrt{ }$ \\
\hline $17-b$ & & $\sqrt{ }$ & 104 & 130 & Bar Slippage & \\
\hline
\end{tabular}

\section{MANUFACTURE AND TESTING OF THE MECHANICAL COUPLER CONNECTS A STRAIGHT ALIGNED BARE:}

Branches of L-shape mechanical coupler are transfer the tension stresses from threaded bar to the other branch which in turn transmits the stresses to the other bar. Due to the difficulty of fixing and testing the L-shaped mechanical coupler and pulled the reinforcing bar from it and that's the important part of this coupler to be tested is the threaded portions, two types of straight mechanical couplers were chosen from the same material of the L-shaped coupler to be tested. The reason of this test is to make sure that the failure will not occur in the coupler branches and that the threads will not loosened from the reinforcing bar. Three samples from coupler connect one aligned reinforcing bar as well as other three couplers connect two aligned reinforcing bars for each are tested.

\subsection{Fabrication steps:}

a. Strips with predetermined dimensions were cut from a plate has the same mechanical properties as the steel plate used to manufacture the L-shaped mechanical coupler.

b. The CNC Plasma Cutting Machine was used for taking out the strips in step 1. Then the strip with cuboidal shapeis converted into a cylindrical shape of a $30 \mathrm{~mm}$ diameter using lathe machine.

c. Lengths of strips used for making the coupler that couple two aligned bars are $60 \mathrm{~mm}$ and 250 for couple one reinforcing bar. The coupling portion of the second length is $50 \mathrm{~mm}$ while the remaining $200 \mathrm{~mm}$ is used to attach fix the mechanical coupler to the testing machine.

d. The coupler samples are drilled and threaded with the predetermined lengths either $30 \mathrm{~mm}$ for L-shaped coupler or $50 \mathrm{~mm}$ in straight coupler.

e. The end of all reinforcing bars are enlarged and then threaded to matching the threads of internal threads of couplers.

f. Figure 17 showed the two types of mechanical couplers after fabrication. 
g.

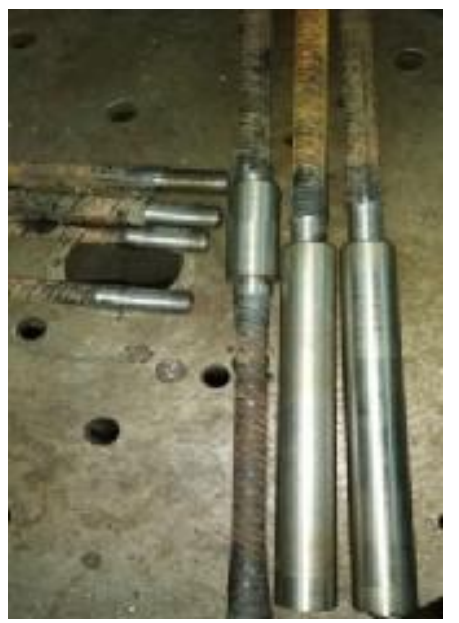

Figure 17: Couplers that connect one bar for each and a coupler connects two aligned bars.

\subsection{Specimens testing:}

The mechanical coupler and the reinforcing bars are fixed at the Tensile Test Machine. Once the specimens were fixed, direct tensile force was applied until the specimen fall. Figure 18 showed the test set-up for both two types of mechanical couplers.

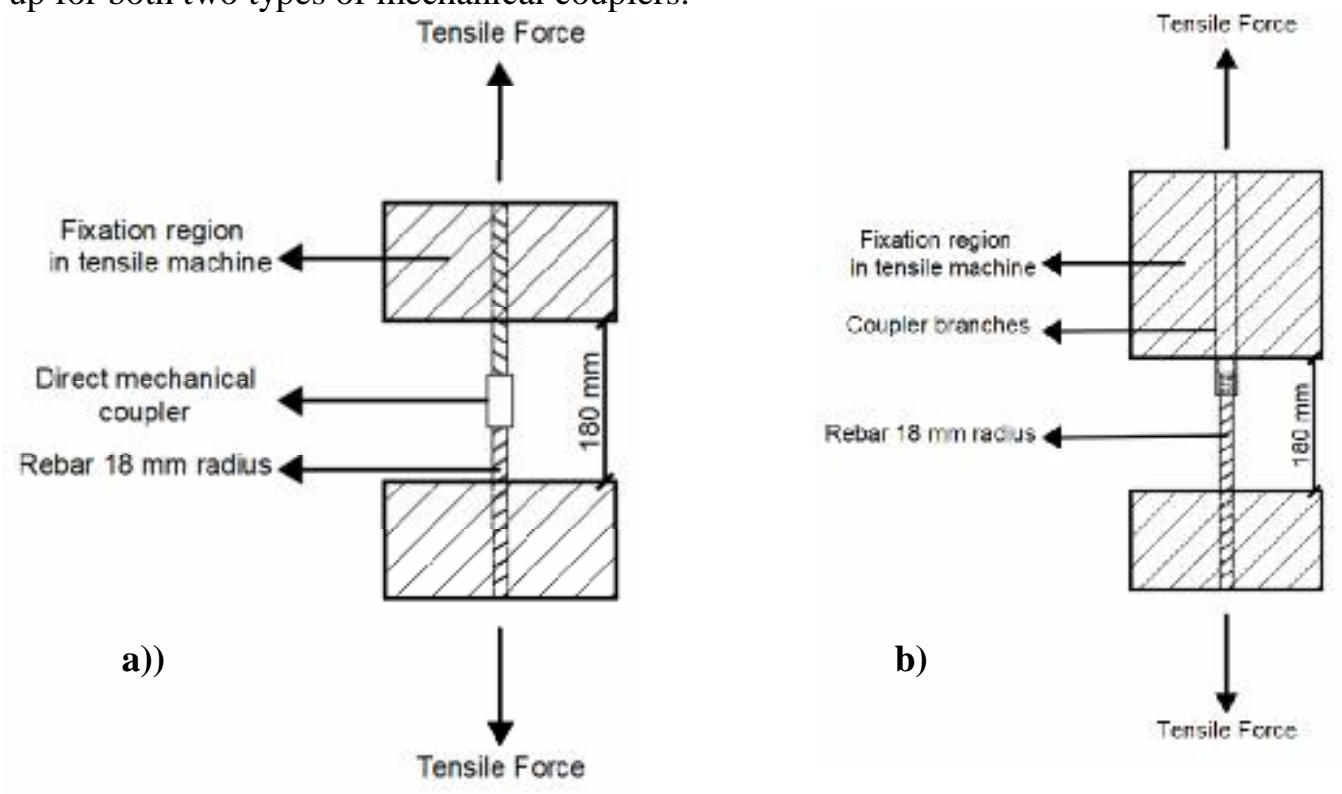

Figure 18: Test set-ups for the two types of mechanical couplers.

The result of test showed that, all specimens failed at rebar out of couplers. The specimens with direct coupler failed at loads $138 \mathrm{kN}, 140.5 \mathrm{kN}$ and $140 \mathrm{kN}$. The specimens fixed in coupler branch the failure loads are $135 \mathrm{kN}, 140 \mathrm{kN}$ and $140 \mathrm{kN}$ and displacement is $10 \mathrm{~mm}, 20 \mathrm{~mm}$ and $20 \mathrm{~mm}$. Figure 19 showed the specimen fixed at coupler immediately before failure at load 160 $\mathrm{kN}$. 


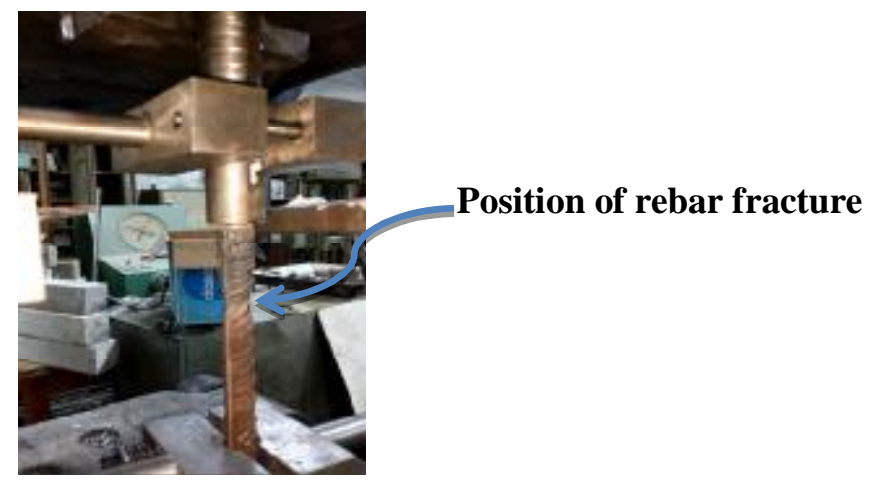

Figure 19: Photo immediately before fracture of rebar at load $160 \mathrm{kN}$.

\section{CONCLUSIONS}

- $\quad$ Threaded L-shaped mechanical couplers were designed, manufactured and tested to connect two ends of two perpendicular reinforcing bars for transferring the stresses between them instead of using one bar bent in a shape of an $\mathrm{L}$ to be used in the knee corner joint. The strength of the mechanical coupler had been designed to ensure that the fracture occurs in the reinforcing rod outside the threading portion (coupling portion). The bar end threaded and the internal threaded of the mechanical coupler had been designed to achieves complete interfere between them in order to prevent slippage that may occur during loading. To demonstrate the importance of increasing the rebar end diameters before threading, so as not to affect the nominal diameter of the bars, a number of mechanical couplers were coupled enlarged reinforcing bar ends and compared with others couplers couple bars did not enlarged its ends. The results of the tensile tests showed that the fatigue occurred of the bars whose diameter was increased outside the coupler while the fatigue were inside the coupled part of the bar whose ends were not increased before threading.

\section{REFERENCES}

1. Kemp E.L. and P.R. Mukherjee. (1968). "Inelastic behavior of concrete knee-joints". The Consulting Engineer.

2. Mayfield, B.; Kong, F. K.; Bennison, A.; and Davies, J. C. D. T. (1971). "Corner Joint Details in Structural Lightweight Concrete". ACI Journal, V. 68, No. 5, pp. 366-372.

3. Zouzou and D. Haldane. (1993). "Detailing reinforced concrete closing corner joints for ductility". Structures and Buildings, 99(1): 43-48.

4. Morgan Johansson. (2000). "Structural Behaviour in Concrete Frame Corners of Civil Defence Shelter". PhD thesis, Chalmers University of Technology, Division of Concrete Structures, Department of Structural Engineering. Göteborg, Sweden.

5. Restrepo, J.I., Crissafulli, F.J. and Park, R.. (1999). "How Harmful is Bending/Straightening of Reinforcing Bars?", Concrete International, Journal of ACI.

6. Babaei, K., and Hawkins, N. M. (1991). "Development of Standard Specifications for Bending/Straightening Concrete Reinforcing Steel". Final Report (No. WA-RD 216.1).

7. G.T. Van Rooyen (1986). "The embrittlement of hardened, tempered low-alloy steel by strain aging". Journal of the South African Institute of Minining Metallurgy, vol. 86, no. 2.(1986): 67-72.

8. Miyagawa, T., Seto, K., Sasaki, K., Mikata, Y., Kuzume, K., and Minami, T. (2006), "Fracture of Reinforcing Steels in Concrete". Structures Damaged by Alkali-Silica Reaction. Journal of Advanced Concrete Technology, 4(3), 339-355.

9. Zhao, Stephen. (2016). "Setting bar-bending requirements for high-strength steel bars". $\mathrm{PhD}$ diss. 
L-SHAPED MECHANICAL COUPLER FOR RC CORNER JOINT

10. Cha, W. G., and Kim, N. (2014). "Quantification of micro-cracks on the bending surface of roll formed products using the GTN model". Metals and Materials International, 20(5), 841-850.

11. Seliem, H. M., Lucier, G., Rizkalla, S. H., and Zia, P. (2008). "Behavior of concrete bridge decks reinforced with high-performance steel". ACI Structural journal, 105(1), 78.

12. Altuhami, A., (2015). International patient application no. WO/2016/138912, https://patentscope. wipo.int/search/en/detail.jsf?docId=WO2016138912.

13. Do-Kyu, H., Kim, H. Y., Choi, H. H., Park, G. B., and Lee, J. H. (2015). "Assessing the Seismic Performance of Threaded Rebar Coupler System". World Academy of Science, Engineering and Technology International Journal of Civil, Environmental, Structural, Construction and Architectural Engineering Vol:9, No:10.

14. NGUYEN, D. P., and Mutsuyoshi, H. (2015). "Influence of Quality of Mechanical Splices on Behavior of Reinforced Concrete Members". Research Report of Department of Civil and Environmental Engineering, Saitama Univ, 41, 32-43.

15. Harinkhede, S., and Varghese, V. (2019). "Performance of Reinforcement Connections in Concrete Structures as an Alternative to Lap Splices". Available at SSRN 3368893.

16. Ahmed Yaseen (2020), "Behavior of exterior beam column joint with coupled reinforcement". MSC thesis, Faculty of engineering, Ain-Shams university. 